\title{
Climatic and anthropogenic impacts on runoff changes in the Songhua River basin over the last 56 years (1955-2010), Northeastern China
}

\author{
Suiji Wang a,*, Yanjun Wang a,b, Lishan Ran ${ }^{\mathrm{c}}$, Teng Su ${ }^{\mathrm{a}, \mathrm{b}}$ \\ a Key Laboratory of Water Cycle and Related Land Surface Processes, Institute of Geographic Sciences and Natural Resources Research, Chinese Academy of Sciences, Beijing 100101, China \\ b University of Chinese Academy of Sciences, Beijing 100049, China \\ c Department of Geography, National University of Singapore, 117570, Singapore
}

\section{A R T I C L E I N F O}

\section{Article history:}

Received 22 June 2014

Received in revised form 16 December 2014

Accepted 5 January 2015

Available online 14 January 2015

\section{Keywords:}

Runoff changes

Precipitation

Evapotranspiration

Human activities

Songhua River basin

\begin{abstract}
A B S T R A C T
Runoff of some rivers in the world has decreased significantly due to climate change and enhanced human activities, resulting in severe eco-environmental problems. As a large Asian river with a channel length of $2309 \mathrm{~km}$ and a basin area of $5.568 \times 10^{5} \mathrm{~km}^{2}$, the Songhua River basin is an important bread basket in China. Although its runoff has experienced dramatic changes over the last decades, the relative importance of climate and human activity on the runoff changes has not been assessed heretofore. The purpose of this study is to decouple the relative impacts of precipitation, evapotranspiration (ET), and human activity on the runoff changes in the river basin using a SCRCQ method. Based on annual runoff dataset at 3 gauging stations on the main stem channel during the period 1955-2010, three turning years of runoff changes were detected that divided the entire time period into four parts for the above Dalai (1963, 1982, and 1998) and Haerbin-Jiamusi (1966, 1980, and 1998) sub-basins. While for the Dalai-Haerbin sub-basin, only one turning year of 1988 was detected. The first period was taken as the reference baseline period while the others regarded as measure periods. Based on mean annual precipitation and mean annual reference crop ET observed at 62 meteorological stations during the period 1955-2010, the relative impacts of precipitation, evapotranspiration and human activities on runoff changes were assessed. For the runoff changes in the above Dalai and Haerbin-Jiamusi sub-basins, the results show that the precipitation impact ranged from $3.3 \%$ to $24.7 \%$ and from $15.4 \%$ to $33.9 \%$, respectively, and the impact of ET ranged from $0.6 \%$ to $10.8 \%$ and from $-7.3 \%$ to $9.8 \%$, respectively. In comparison, the anthropogenic impact ranged from $64.8 \%$ to $96.1 \%$ and from $56.3 \%$ to $91.9 \%$, respectively. For the Dalai-Haerbin sub-basin, the impacts of precipitation, evapotranspiration and human activities on the runoff changes were $29.7 \%,-15.6 \%$ and $85.8 \%$, respectively. Human activities have become the most important factor in controlling runoff changes in the river basin. The magnitude of human impact reached its maximum in the 1990s, and then decreased remarkably as a result of the implementation of some new measures, such as water-saving irrigation, wetland conservation and restoration, and reforestation, in agriculture production and environment protection. Given the severe water stress, anthropogenic impact on runoff changes in the Songhua River basin must be given more attention in the future.
\end{abstract}

(C) 2015 Elsevier B.V. All rights reserved.

\section{Introduction}

River runoff is one of the most important water resources for people throughout the world. Its annual changes are commonly the combined results of natural factors and human activities. The runoff of the world's rivers has been significantly altered by both climate change and human activities over the past decades (e.g., Nilsson et al., 2005; Miao et al., 2011; Wang et al., 2012a,b). As a consequence, the annual runoff of many rivers decreased remarkably in the last decades (Wang et al., 2012a), causing a number of water resources problems, in particular in arid and semi-arid regions (Vörösmarty et al., 2000).

\footnotetext{
* Corresponding author.

E-mail address: wangsj@igsnrr.ac.cn (S. Wang).
}

The causes of changes in river runoff differ from river to river and vary through time (Wu et al., 2012). To manage water resources more efficiently, it is necessary to understand runoff generation and variation under changing environments (Askew, 1987; Burn, 1994; Arnell, 1999; Drogue et al., 2004; Xu, 2011; Wang et al., 2012a). Furthermore, quantitative assessment of the relative impacts of different factors on runoff changes for specific rivers is a precondition for sustainable water resource management and exploitation. The influencing factors on runoff changes are mainly climate, including precipitation and evapotranspiration, and human activities. Numerous studies have examined recent runoff changes and their responses to climate change in worldwide river basins (e.g., Richey et al., 1989; Schulze, 2000; Poveda et al., 2001; Chiew and Mcmahon, 2002; Merritt et al., 2006; Cao et al., 2011; McCabe and Wolock, 2011; Islam et al., 2012; Tang et al., 2012; Yan et al., 2013; Lei et al., 2014). The impacts of human activities on 
runoff changes at the watershed scale are temporarily significant, at least over the last decades. Several researchers have recently paid more attention to the integrated climatic and anthropogenic impacts on runoff changes (e.g., Milliman et al., 2008; Ma et al., 2008). However, few studies have assessed the exact influences of climate change and human activities on runoff changes. Wang et al. (2012a) have indicated that quantitative assessment of the relative influences of climate change and human activity on runoff changes remains an important scientific issue in hydrology to be properly solved.

As the third largest river in China in terms of basin area and runoff, the Songhua River provides freshwater for about 58.3 million people (Fig. 1). In particular, the population of five large cities (Haerbin, Changchun, Daqing, Qiqiharer, and Jilin) within the river basin exceeds one million. The Songhua River basin is also one of the three famous regions of black soil land worldwide. It has become a Chinese national production base for agriculture and forestry because of the fertility of the blank soils (Miao et al., 2011). The shortage of water resources in the river basin, like in the many other river basins in Northern China, has become a severe problem due to rapid growth of population, urbanization, and economy during the past decades. Although several studies have focused on the runoff changes at certain hydrological gauge stations, tributaries, and even the whole basin of the Songhua River (e.g., Song et al., 2009; Xu et al., 2009; Feng et al., 2011; Miao et al., 2011; Meng and Mo, 2012; Pan and Tang, 2013; Wang et al., 2014), quantifying the relative influences of the integrated climatic and anthropogenic factors on the runoff changes in the river basin has seldom been investigated.

Apparently, while these studies on the runoff changes in the river basin analyzed only the runoff change trend, the relative importance of differing factors on runoff changes was not explicitly evaluated owing to the difficulties to differentiate the relative impacts of various factors. As has been frequently indicated, human impacts have been a dominant factor in affecting drainage runoff variations. In view of the

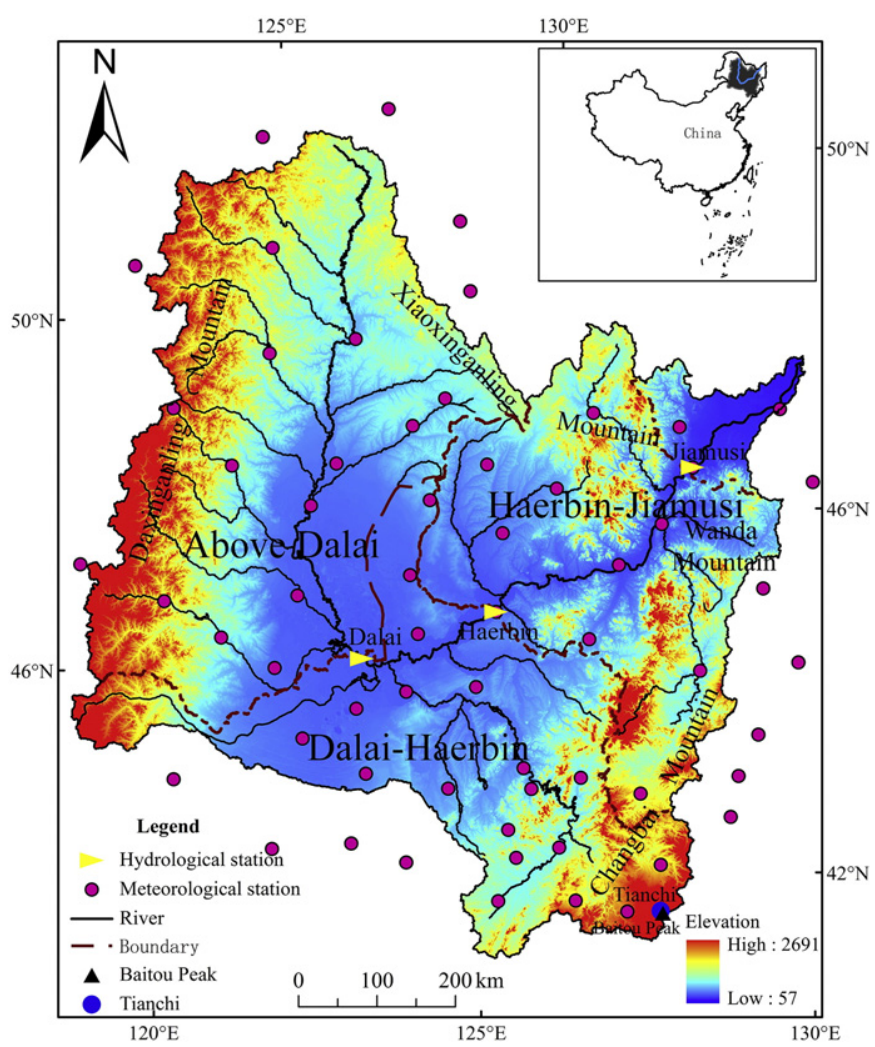

Fig. 1. Location map of the Songhua River basin showing three hydrological gauging stations along the main stem channel and 62 meteorological stations (46 stations within and 16 stations around the river basin). accelerated magnitude of human impacts within the river basin, it is highly necessary to quantify the relative impacts of climate change and human activities on the runoff changes for a better water resource management.

This study focuses on the runoff variations at three different river sub-basins and also the whole Songhua River basin during the period 1955-2010. The major objectives are: 1) to identify the turning years in runoff variations, which will be used to divide the whole period into a reference baseline period and measure periods; 2 ) to quantify the relative influences of precipitation, evapotranspiration, and human activities on runoff changes in the river sub-basins and the whole river basin based on the slope change ratio of cumulative quantity (SCRCQ) method by comparing the values in the measure periods with that in the reference baseline period; and 3) to discuss the main influencing modes of human activities on the runoff changes. This work will provide important insights into future sustainable water resource management and planning for other rivers suffering from similar human and natural impacts.

\section{Environmental setting}

Located in Northeastern China $\left(119^{\circ} 52^{\prime}-132^{\circ} 31^{\prime} \mathrm{E}, 41^{\circ} 42^{\prime}-51^{\circ} 38^{\prime}\right.$ $\mathrm{N})$, the Songhua River originates from the northern part of the Daxinganling (Greater Khingan) Mountain and flows first southward then northeastward at the Sanchahe, before joining the Heilongjiang River at the outlet of the river basin. With a drainage area of $5.57 \times 10^{5} \mathrm{~km}^{2}$ (Fig. 1), it occupies a large part of the Heilongjiang and Jilin provinces, the northeastern part of the Inner Mongolia Autonomous Region and a small part of the Liaoning Province (Miao et al., 2011). The proportion of the basin area within the Heilongjiang, Jilin, and Liaoning provinces and the Inner Mongolia Autonomous Region is $48.17 \%, 24.23 \%, 0.09 \%$, and $27.51 \%$, respectively. The ridge of the Daxinganling Mountain is the northwestern watershed and the ridge of the Changbai Mountain is the southeastern watershed of the Songhua River basin. The southwestern and northeastern boundaries of the river basin are the ridges of the hills and Wanda Mountain, respectively (Fig. 1). In the river basin the highest elevation is $2691 \mathrm{~m}$ at the Baitou Peak of the Changbai Mountain and the lowest is about $57 \mathrm{~m}$ at the river outlet. The Songnen and Sanjiang Plains with an elevation of 57-128 $\mathrm{m}$ are situated in the central and eastern parts, respectively. The areas of mountain, hill, and plain within the basin account for $42.7 \%, 29.1 \%$ and $27.4 \%$, respectively, of the total drainage area. With a mean annual temperature of $3-5^{\circ} \mathrm{C}$, the mean monthly temperature difference is seasonally significant. It is less than $-20{ }^{\circ} \mathrm{C}$ in January while $25^{\circ} \mathrm{C}$ in July. The mean annual precipitation in the river basin is $525.6 \mathrm{~mm}$ during the period 1955-2010. Particularly, precipitation in the flood season (Jun.-Sep.) of $390.8 \mathrm{~mm}$ can account for about $77.6 \%$ of the annual total precipitation (Liu et al., 2012). In comparison, the precipitation in the period of Dec.-Feb. is very low and represents only $5 \%$. Spatial distribution of precipitation is also uneven across the river basin. The mean annual precipitation in the southeastern part of the river basin is about $700-800 \mathrm{~mm}$ while in the western part is just $400 \mathrm{~mm}$.

With a total channel length of $2309 \mathrm{~km}$, the average channel gradient is about 0.00042 . The river reach above Sanchahe is commonly referred to as the Nenjiang River, which has a channel length of $1370 \mathrm{~km}$ and a channel gradient of 0.00066 . As the largest tributary of the Songhua River, the Second Songhua River with a channel length of $795 \mathrm{~km}$ and a channel gradient of 0.00196 originates from the Tianchi Lake located in the central part of the Changbai Mountain, flows northwestward and joins the Songhua River at Sanchahe. The channel below Sanchahe has a channel length of $939 \mathrm{~km}$ with a channel gradient of 0.000076 . The mean runoff of the Songhua River during the period $1955-2010$ was about $6.32 \times 10^{10} \mathrm{~m}^{3} \mathrm{yr}^{-1}$, which is substantially lower than the $7.59 \times 10^{10} \mathrm{~m}^{3} \mathrm{yr}^{-1}$ for the period 1950s-1970s. Six hydrological gauging stations were established along the main stem 
channel in 1955. The lowermost Jiamusi Station (Fig. 1) controls a drainage area of $5.28 \times 10^{5} \mathrm{~km}^{2}$, accounting for $94.8 \%$ of the total drainage area.

Geographically, the upper reach of the Songhua River is above the Dalai Station and is also called Nenjiang River, the middle reach extends from Dalai to Haerbin, and the lower reach is below the Haerbin Station. As the largest tributary, the Second Songhua River joins the main stem in the middle reach. Considering the environment and landform characteristics of the drainage basin, we divided the whole river basin into three sub-basins using three major hydrological stations (i.e., Dalai, Haerbin, and Jiamusi, see Fig. 1), including above Dalai, Dalai-Haerbin, and Haerbin-Jiamusi. The drainage area of the three sub-basins is about $2.22,1.68$, and $1.39 \times 10^{5} \mathrm{~km}^{2}$, respectively (Table 1 ).

\section{Materials and methods}

\subsection{Materials}

Data used in this study included annual runoff at Dalai, Haerbin and Jiamusi stations (Fig. 1), and annual mean precipitation and ET for the sub-basins of above Dalai, Dalai-Haerbin, and Haerbin-Jiamusi as well as the total drainage basin above Jiamusi station. The observed series cover the period from 1955 to 2010. In addition, the annual runoff for the three stations was retrieved from the Hydrologic Yearbooks of Heilongjiang River Basin (Bureau of Hydrology, Ministry of Water Resources of People's Republic of China, 1955-2010).

Annual runoff for the sub-basin of above Dalai and for the whole river basin equals to the annual runoff gauged at Dalai Station and Jiamusi Station, respectively. For the Dalai-Haerbin and Haerbin-Jiamusi sub-basins, the annual runoff is calculated by deducting the runoff input from the runoff output. The annual runoff is defined as the total runoff generated minus the total consumed water in each sub-basin (net runoff in each sub-basin) (Wang et al., 2012a).

With annual precipitation data at 62 meteorological stations within and around the Songhua River basin during the period 1955-2010, the annual precipitation across the river basin was determined using the Kriging interpolation method in ArcGIS 9.3 (Wang et al., 2012a) (Fig. 1). In total, 56 precipitation distribution maps were generated (e.g., Fig. 2). The annual mean precipitation for each sub-basin was derived using the precipitation distribution maps within the corresponding drainage boundary of each sub-basin.

Daily data of mean temperature, highest and lowest temperature, mean humidity, mean wind speed, sunshine duration, and mean air pressure for the 62 meteorological stations were adopted to calculate the annual potential ET for each station during the period 1955-2010. The meteorological data were downloaded from the China Meteorological Data Sharing Service System (http://cdc.cma.gov.cn/home.do). The annual mean potential ET for the whole river basin and each sub-basin was obtained with the same procedure as we did for the annual mean precipitation.

\subsection{Methods}

Main methods used in this study are the cumulative anomaly, the Penman-Monteith (PM) equation, and the SCRCQ method.

Table 1

Physical characteristics of different sections in the Songhua River basin.

\begin{tabular}{lllll}
\hline Sections & $\begin{array}{l}\text { Drainage } \\
\text { area } \\
\left(\mathrm{km}^{2}\right)\end{array}$ & $\begin{array}{l}\text { Mean annual } \\
\text { runoff }\left(10^{8}\right. \\
\left.\mathrm{m}^{3} \mathrm{yr}^{-1}\right)\end{array}$ & $\begin{array}{l}\text { Mean annual } \\
\mathrm{precipitation}_{\left(\mathrm{mm} \mathrm{yr}^{-1}\right)}\end{array}$ & $\begin{array}{l}\text { Mean annual } \\
\text { reference crop ET } \\
\left(\mathrm{mm} \mathrm{yr}^{-1}\right)\end{array}$ \\
\hline Above Dalai & 221,715 & 205.91 & 468.1 & 611.7 \\
Dalai-Haerbin & 168,054 & 200.57 & 567.6 & 676.9 \\
Haerbin-Jiamusi & 138,508 & 225.28 & 573.0 & 601.8 \\
Above Jiamusi & 528,277 & 631.76 & 525.6 & 626.4
\end{tabular}

The cumulative anomaly was used to identify the turning year in runoff changes for the three sub-basins and the whole river basin during the period 1955-2010. The identified turning years via this method was further used to divide the whole period into climate-driven period (reference baseline period) and human-driven period (measure period) (Wang et al., 2012b).

As recommended by FAO (Allen et al., 1998), the PM equation derived from the classic Penman equation (Penman, 1948) can be used to estimate the daily potential ET (Zuo et al., 2012). The PM equation can be expressed as below,

$E T_{0}=\frac{0.408 \Delta\left(R_{n}-G\right)+r \frac{900}{T+273} U_{2}\left(e_{s}-e_{a}\right)}{\Delta+r\left(1+0.34 U_{2}\right)}$

where $E T_{0}$ is the reference crop ET $\left(\mathrm{mm} \mathrm{d}^{-1}\right), R_{n}$ is the net radiation at the crop surface $\left(\mathrm{MJ} \mathrm{m} \mathrm{m}^{-2} \mathrm{~d}^{-1}\right), G$ is the soil heat flux density $\left(\mathrm{MJ} \mathrm{m} \mathrm{m}^{-2} \mathrm{~d}^{-1}\right.$ ) (at daily scale it is negligible, i.e., $G_{\text {day }} \sim 0$ ), $T$ is the mean daily air temperature at a height of $2 \mathrm{~m}\left({ }^{\circ} \mathrm{C}\right), U_{2}$ is the wind speed at a height of $2 \mathrm{~m}\left(\mathrm{~m} \mathrm{~s}^{-1}\right), e_{s}$ is the saturation vapor pressure $(\mathrm{kPa}), e_{a}$ is the actual vapor pressure ( $\left.\mathrm{kPa}\right), \Delta$ is the slope vapor pressure curve $\left(\mathrm{kPa}{ }^{\circ} \mathrm{C}^{-1}\right)$ and $r$ is the psychrometric constant $\left(\mathrm{kPa}^{\circ} \mathrm{C}^{-1}\right)$, and the corrected $R_{n}$ by Yin et al. (2008) is adopted.

Using this equation, we calculated the annual reference crop ET for each meteorological station based on daily reference crop ET. Then, the annual potential ET across the river basin was generated through Kriging interpolation in ArcGIS 9.3. In total, 56 annual potential ET maps were generated. Fig. 3 illustrates the annual potential ET in the river basin in typical years. The annual mean potential ET for each sub-basin was derived using the potential ET distribution map within the corresponding drainage boundary of each sub-basin.

The SCRCQ method (Wang et al., 2012a) was used to quantify the relative influences of climate change (including precipitation and potential ET) and human activities on runoff changes in a river basin or its sub-basins. Quantitative influences of precipitation, potential ET, and human activities on runoff changes in the three sub-basins and in the whole river basin can be calculated via the equations (Wang et al., 2012a) below and is expressed as $C_{P}, C_{E}$, and $C_{H}$, respectively.

$$
\begin{aligned}
& C_{P}=100 \times\left(\left(S_{P a}-S_{P b}\right) /\left|S_{P b}\right|\right) /\left(\left(S_{R a}-S_{R b}\right) /\left|S_{R b}\right|\right) \\
& C_{E}=-100 \times\left(\left(S_{E a}-S_{E b}\right) /\left|S_{E b}\right|\right) /\left(\left(S_{R a}-S_{R b}\right) /\left|S_{R b}\right|\right) \\
& C_{H}=100-C_{P}-C_{E}-C_{G}
\end{aligned}
$$

where $S$ is the slope of the linear relationship between year and cumulative runoff (labeled by subscript $R$ ), cumulative precipitation (labeled by subscript $P$ ) or cumulative potential ET (labeled by subscript $E$ ) in the baseline period or a measure period. Subscripts $a$ and $b$ denote the measure periods and reference baseline period, respectively. $C_{G}$ represents the impact of groundwater on the runoff changes. It is negligible at an annual scale (i.e., $C_{G} \sim 0$ ).

\section{Results}

\subsection{Changes in annual runoff and their turning years}

The annual runoff during the period 1955-2010 at the three stations presented different temporal variations (Fig. 4). While the runoff decreased before 1980, it showed an increasing trend in the 1980s in all the three sub-basins. The annual runoff in the 2000s was significantly lower than that in 1990s. Average runoff for the three sub-basins during the period $1955-2010$ was $205.91,200.57$, and $225.28 \times 10^{8} \mathrm{~m}^{3}$, respectively. The anomaly (annual value minus average value) of the annual runoff in the three sub-basins during the period 1955-2010 ranged from -157.9 to $415.19 \times 10^{8} \mathrm{~m}^{3}$, from -106.97 to $125.43 \times 10^{8} \mathrm{~m}^{3}$, 


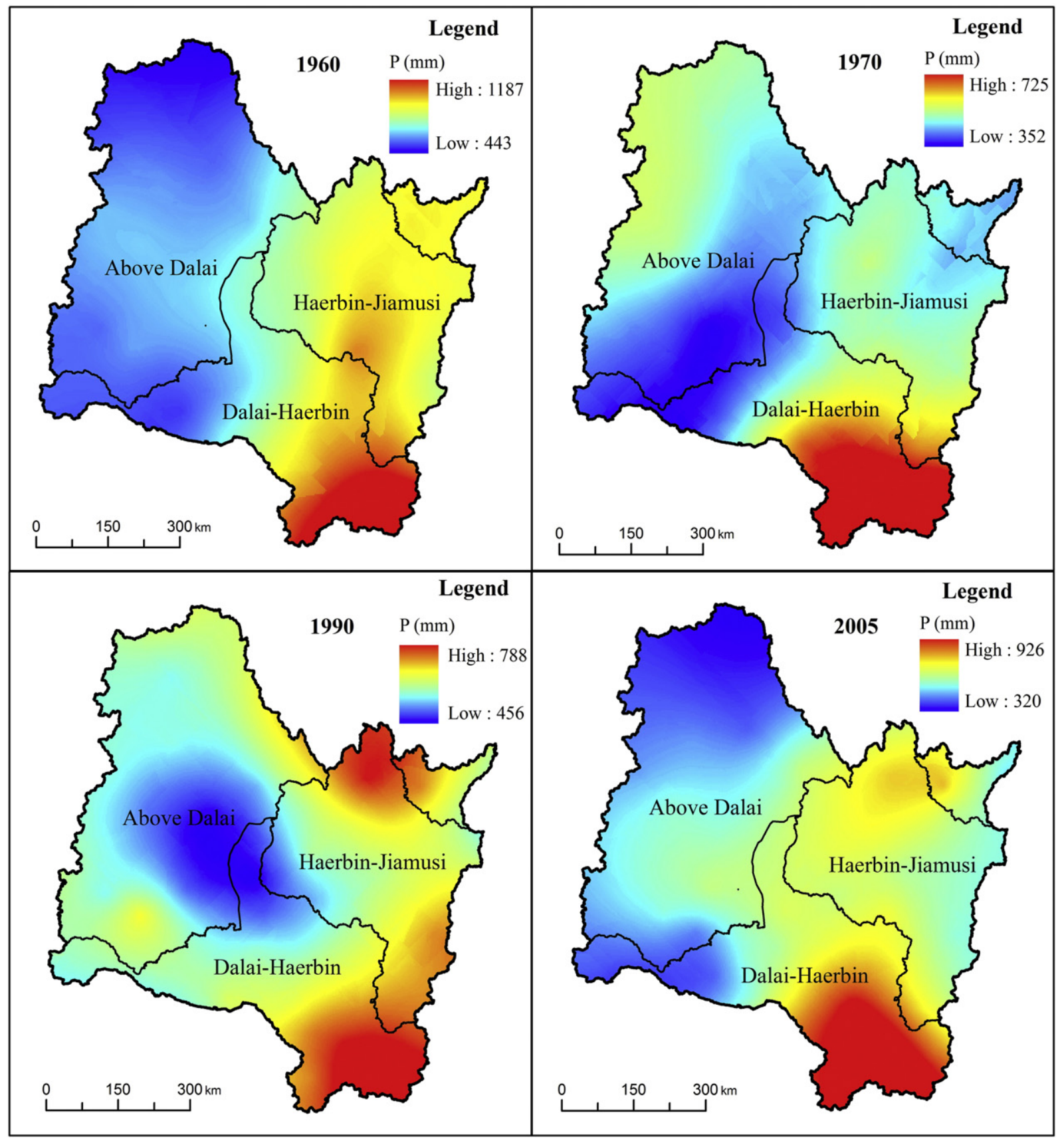

Fig. 2. Spatial distribution of annual precipitation in the Songhua River basin in typical years.

and from -138.94 to $238.22 \times 10^{8} \mathrm{~m}^{3}$, respectively. With the extreme floods in 1998 across the river basin, its annual runoff reached 621.1, 215.5 , and $287.6 \times 10^{8} \mathrm{~m}^{3}$ (Fig. 4), which is $2.7,1.1$, and 1.3 times the average annual runoff for the three sub-basins, respectively. In addition, the large water discharge event mainly occurred in the upper reach above the Dalai Station (Fig. 4).

The turning years in the runoff changes are 1963, 1982, and 1998 for the above Dalai sub-basin, 1988 for the Dalai-Haerbin sub-basin and 1966, 1980, and 1998 for the Haerbin-Jiamusi sub-basin (Fig. 5). Changes of the runoff in the above Dalai sub-basin are similar to that in the Haerbin-Jiamusi sub-basin. For the Dalai-Haerbin sub-basin, only one turning year of 1988 was identified, which is different from the other sub-basins. As such, the periods of 1955-1963, 1955-1966, and 1955-1988 can be regarded as the reference baseline period for the runoff changes for the above Dalai, Dalai-Haerbin, and Haerbin-Jiamusi sub-basins. The mean runoff was 317.7, 218.1, and
$316.1 \times 10^{8} \mathrm{~m}^{3} \mathrm{yr}^{-1}$, respectively, for the three sub-basins. Other periods (i.e. 1964-1982, 1983-1998, and 1999-2010 for the above Dalai sub-basin, 1989-2010 for the Dalai-Haerbin sub-basin, and 1967-1980, 1981-1998, and 1999-2010 for the Haerbin-Jiamusi sub-basin) can be regarded as the measure periods. Compared with the reference baseline period, the mean annual runoff during each measure period for all sub-basins decreased with different reduction rates (Table 2 ).

\subsection{Changes in mean annual precipitation and potential ET}

The mean annual precipitation for the three sub-basins was illustrated in Fig. 6. Similar to the runoff changes, the mean annual precipitation decreased before 1980 and showed an increasing trend in the 1980s in the three sub-basins. A significant decreasing and increasing trend in the precipitation for the sub-basins occurred in the 1990s and 2000s, 


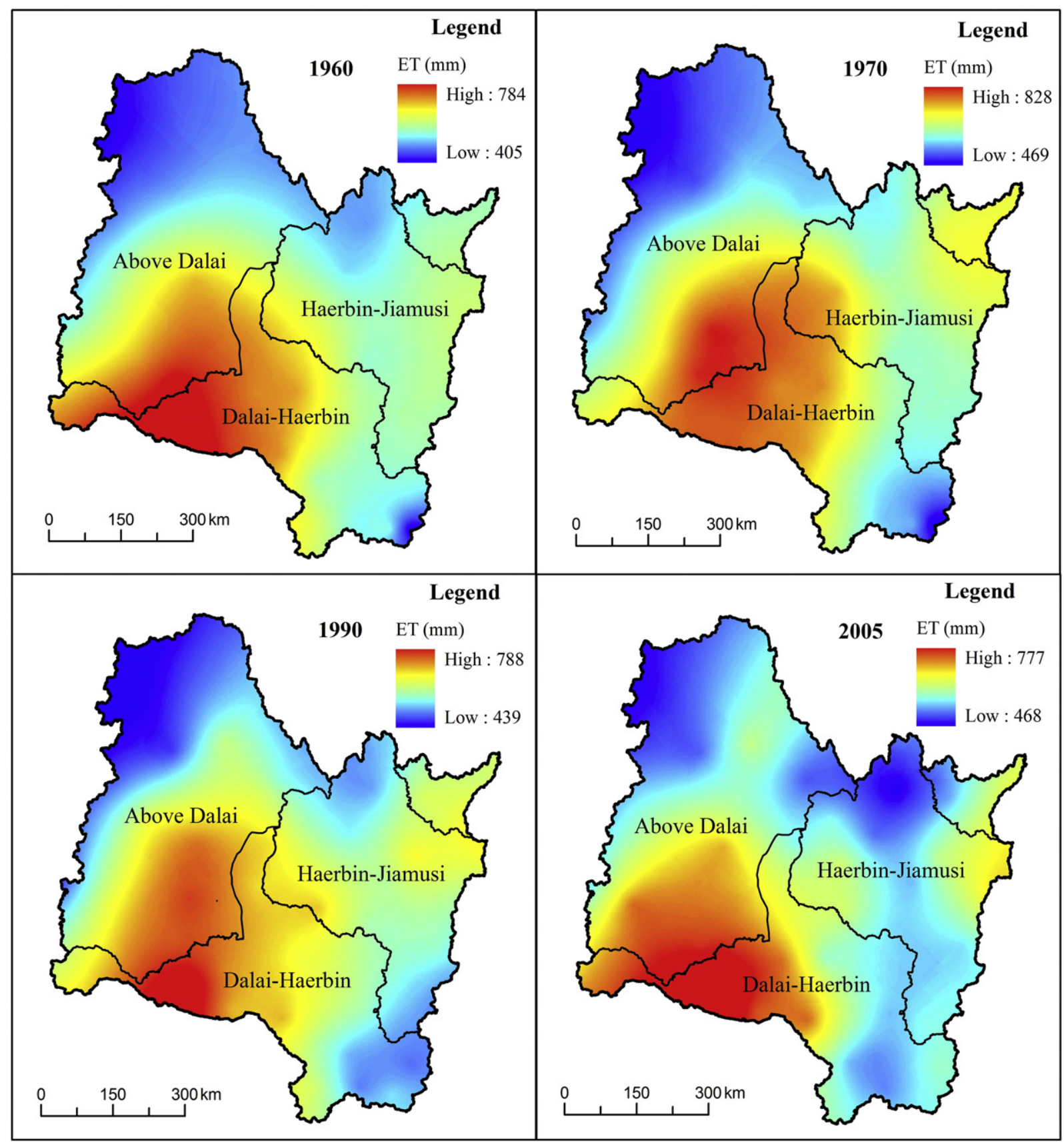

Fig. 3. Spatial distribution of annual potential ET in the Songhua River basin in typical years.

respectively. The average precipitation for the three sub-basins during the whole period was $468.1,567.6$, and $573.0 \mathrm{~mm} \mathrm{yr}^{-1}$, respectively, and showed an upward trend along the sub-basins. The anomaly of the mean annual precipitation in the three sub-basins during the period 1955-2010 ranged from -151.7 to $260.6 \mathrm{~mm}$, from -148.6 to $189.9 \mathrm{~mm}$, and from -152.0 to $184.6 \mathrm{~mm}$, respectively. The strong precipitation in 1998 is considerably higher than that in the other years in the above Dalai sub-basin that induced the great floods in the river basin.

The mean annual potential ET in terms of reference crop ET, calculated from Eq. (1), for the three sub-basins in the Songhua River basin was illustrated in Fig. 7. For all the three sub-basins, while the mean annual ET showed an increasing trend before 1980 and in the 1990s, it presented a decreasing trend in the 1980s and 2000s. The average ET for the three sub-basins during the whole period is 611.7, 676.9, and $601.8 \mathrm{~mm} \mathrm{yr}^{-1}$, respectively, with the anomaly of the mean annual ET ranging from -76 to $59.7 \mathrm{~mm}$, from -75.4 to $101.4 \mathrm{~mm}$, and from -62.5 to $104.9 \mathrm{~mm}$, respectively. The greatest extension in ET anomaly is in the Dalai-Haerbin sub-basin while the least is in the above Dalai sub-basin.

\subsection{Relationships between year and cumulative runoff, precipitation and potential ET}

Fig. 8 shows the relationship between year and cumulative runoff. The fitted lines were divided into several parts by the turning years of runoff changes for the sub-basins of above Dalai, Dalai-Haerbin, and Haerbin-Jiamusi. The best fitted linear relationships between year and cumulative runoff during the reference baseline period and the measure periods for the three sub-basins are also illustrated in Fig. 8. All relationships have a high correlation coefficient of $>0.97$. The slope $\left(S_{R}\right)$ of each fitted line is extracted from the equations in Fig. 8 and listed in Table 2. 

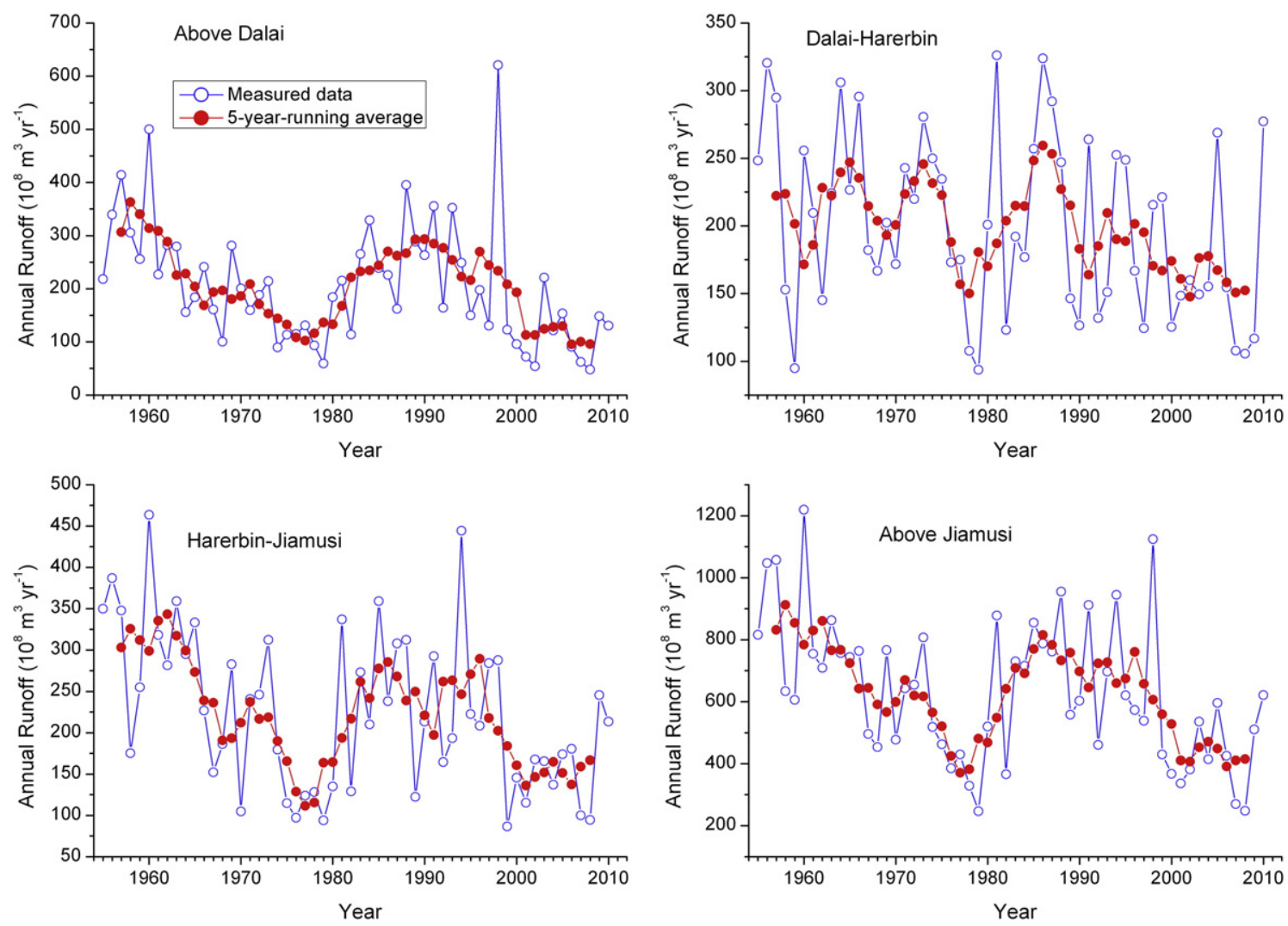

Fig. 4. Temporal variations of mean annual runoff in the above Dalai, Dalai-Haerbin and Haerbin-Jiamusi sections and the whole basin (i.e. above Jiamusi) of the Songhua River.

Similarly, the relationship between year and cumulative precipitation for the three sub-basins in the reference baseline period and different measure periods is illustrated in Fig. 9. All correlation coefficients of the relationships exceed 0.998 . The slope $\left(S_{P}\right)$ of each fitted line is extracted from the equations in Fig. 9 and also listed in Table 2.

Fig. 10 shows the relationship between year and cumulative potential ET (reference crop ET) for the three sub-basins in the reference baseline period and different measure periods. Each relationship has a very high correlation coefficient of $>0.9998$. The slopes $\left(S_{E T}\right)$ of the fitted lines for the reference baseline period and the different measure periods are extracted from the equations in Fig. 10 and also listed in Table 2.

\subsection{Quantification of climatic and anthropogenic influences}

\subsubsection{For the three sub-basins}

Quantitative impacts of precipitation on runoff changes in the three sub-basins during the different measure periods were calculated based on Eq. (2) and the parameters $S_{R}$ and $S_{P}$ in Table 2. The results were presented in Table 3. For the above Dalai sub-basin, it is 24.3 , 3.3, and $24.7 \%$ for the periods of 1964-1982, 1983-1998, and 1999-2010, respectively. For the Dalai-Haerbin sub-basin, it is $29.7 \%$ in the period of $1989-2010$; while for the Haerbin-Jiamusi sub-basin, it is $33.9,15.4$, and $25.7 \%$ for the periods of 1967-1980, 1981-1998, and 1999-2010, respectively.
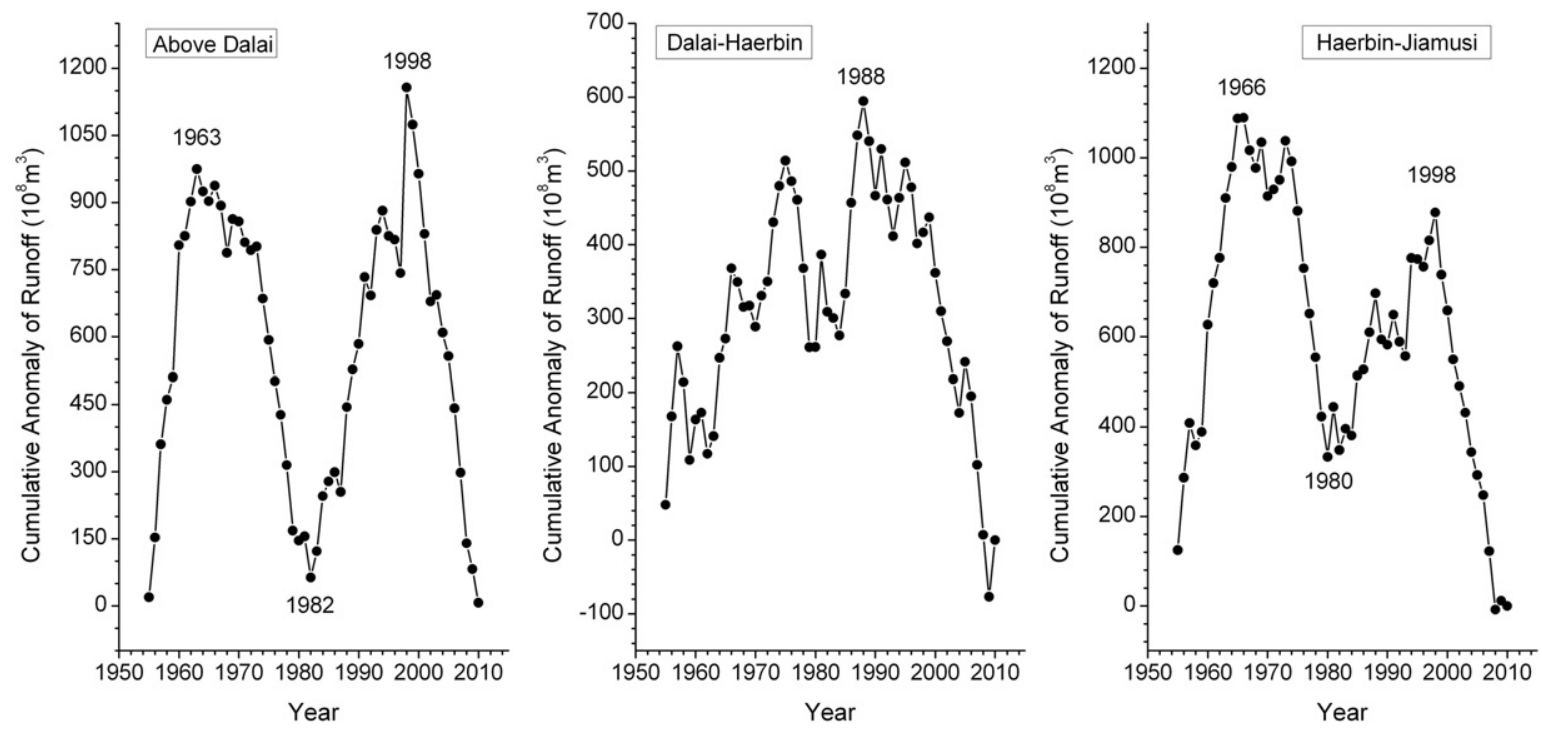

Fig. 5. Change trends of the cumulative anomaly of annual runoff and their turning years in the above Dalai, Dalai-Haerbin and Haerbin-Jiamusi sections of the Songhua River. 
Table 2

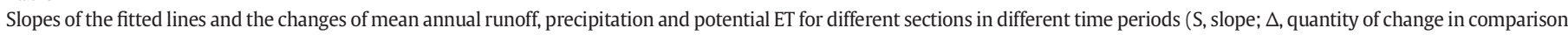
with relative reference baseline period).

\begin{tabular}{|c|c|c|c|c|c|c|c|c|}
\hline \multirow{2}{*}{$\begin{array}{c}\text { Regions } \\
\text { Above Dalai }\end{array}$} & \multicolumn{2}{|c|}{ Periods } & \multirow{2}{*}{$\begin{array}{c}\begin{array}{c}\left.S_{R} \mathrm{yr}^{-1}\right) \\
\left(\times 10^{8} \mathrm{~m}^{3} \mathrm{yr}^{-1}\right)\end{array} \\
335.88\end{array}$} & \multirow{2}{*}{$\begin{array}{c}\Delta R_{m} \\
\left(\times 10^{8} \mathrm{~m}^{3} \mathrm{yr}^{-1}\right)\end{array}$} & \multirow{2}{*}{$\begin{array}{c}\begin{array}{c}S_{P} \\
\left(\mathrm{~mm} \mathrm{yr}^{-1}\right)\end{array} \\
509.47\end{array}$} & \multirow{2}{*}{$\begin{array}{c}\Delta P_{m} \\
\left(\mathrm{~mm} \mathrm{yr}^{-1}\right)\end{array}$} & \multirow{2}{*}{$\begin{array}{c}\begin{array}{c}S_{E T} \\
\left(\mathrm{~mm} \mathrm{yr}^{-1}\right)\end{array} \\
591.77\end{array}$} & \multirow{2}{*}{$\begin{array}{c}\Delta E T_{m} \\
\left(\mathrm{~mm} \mathrm{yr}^{-1}\right)\end{array}$} \\
\hline & Baseline & 1955-1963 & & & & & & \\
\hline & Measure & 1964-1982 & 156.60 & -153.70 & 440.04 & -59.43 & 627.63 & 32.45 \\
\hline & & 1983-1998 & 264.22 & -43.41 & 505.16 & 10.27 & 592.76 & -0.65 \\
\hline & & $1999-2010$ & 110.75 & -207.63 & 422.86 & -83.50 & 627.45 & 36.00 \\
\hline \multirow[t]{2}{*}{ Dalai-Haerbin } & Baseline & $1955-1988$ & 210.11 & & 565.42 & & 688.53 & \\
\hline & Measure & 1989-2010 & 173.96 & -44.52 & 536.49 & -36.93 & 670.09 & -20.76 \\
\hline \multirow[t]{4}{*}{ Haerbin-Jiamusi } & Baseline & 1955-1966 & 315.58 & & 622.23 & & 597.43 & \\
\hline & Measure & 1967-1980 & 176.31 & -144.82 & 529.24 & -98.41 & 623.3 & 27.07 \\
\hline & & 1981-1998 & 251.77 & -60.51 & 602.86 & -22.42 & 588.57 & -0.90 \\
\hline & & 1999-2010 & 154.27 & -163.92 & 540.4 & -89.28 & 592.35 & -1.96 \\
\hline \multirow[t]{4}{*}{ Above Jiamusi } & Baseline & 1955-1966 & 822.01 & & 562.14 & & 620.39 & \\
\hline & Measure & 1967-1982 & 521.81 & -303.61 & 493.59 & -71.07 & 645.32 & 25.47 \\
\hline & & 1983-1998 & 722.45 & -90.80 & 555.28 & -0.23 & 608.56 & -10.34 \\
\hline & & $1999-2010$ & 424.65 & -402.68 & 485.75 & -80.87 & 628.31 & 9.23 \\
\hline
\end{tabular}

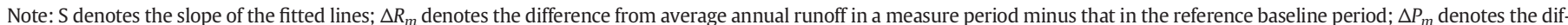

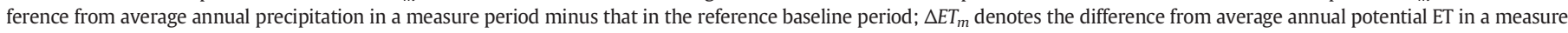
period minus that in the reference baseline period.

Furthermore, based on Eq. (3) and the parameters $S_{R}$ and $S_{E T}$ in Table 2, quantitative impacts of the potential ET on runoff changes in the three sub-basins during different measure periods were calculated (Table 3). For the above Dalai sub-basin it is $10.8,0.6$, and $8.8 \%$ for the periods of 1964-1982, 1983-1998, and 1999-2010, respectively. For the Dalai-Haerbin sub-basin, it is $-15.6 \%$ in the period of $1989-2010$; while for the Haerbin-Jiamusi sub-basin, it is $9.8,-7.3$, and $-1.7 \%$ for the periods of 1967-1980, 1981-1998, and 1999-2010, respectively.

When ignoring the influence of ground water change (i.e., $C_{G}=0$ ), quantitative impacts of human activities on runoff changes in the three sub-basins during different measure periods were calculated using Eq. (4). The results were presented in Table 3. For the above Dalai sub-basin, it is $64.8,96.1$, and $66.6 \%$ for the periods of
1964-1982, 1983-1998, and 1999-2010, respectively. For the DalaiHaerbin sub-basin, it is $85.8 \%$ in the period of $1989-2010$; while for the Haerbin-Jiamusi sub-basin, it is $56.3,91.9$, and $75.9 \%$ for the periods of 1967-1980, 1981-1998, and 1999-2010, respectively.

\subsubsection{For the whole river basin}

While there are three measure periods in the runoff changes for the above Dalai and Haerbin-Jiamusi sub-basins, only one measure period is detected in the Dalai-Haerbin sub-basin. Therefore, it is necessary to test the runoff changes for the whole river basin, and to quantitatively assess the impacts of climatic and anthropogenic factors. As the lowermost gauging station, the area above Jiamusi Station is $528,277 \mathrm{~km}^{2}$ (Table 1), accounting for $94.9 \%$ of the total drainage area. Thus, runoff
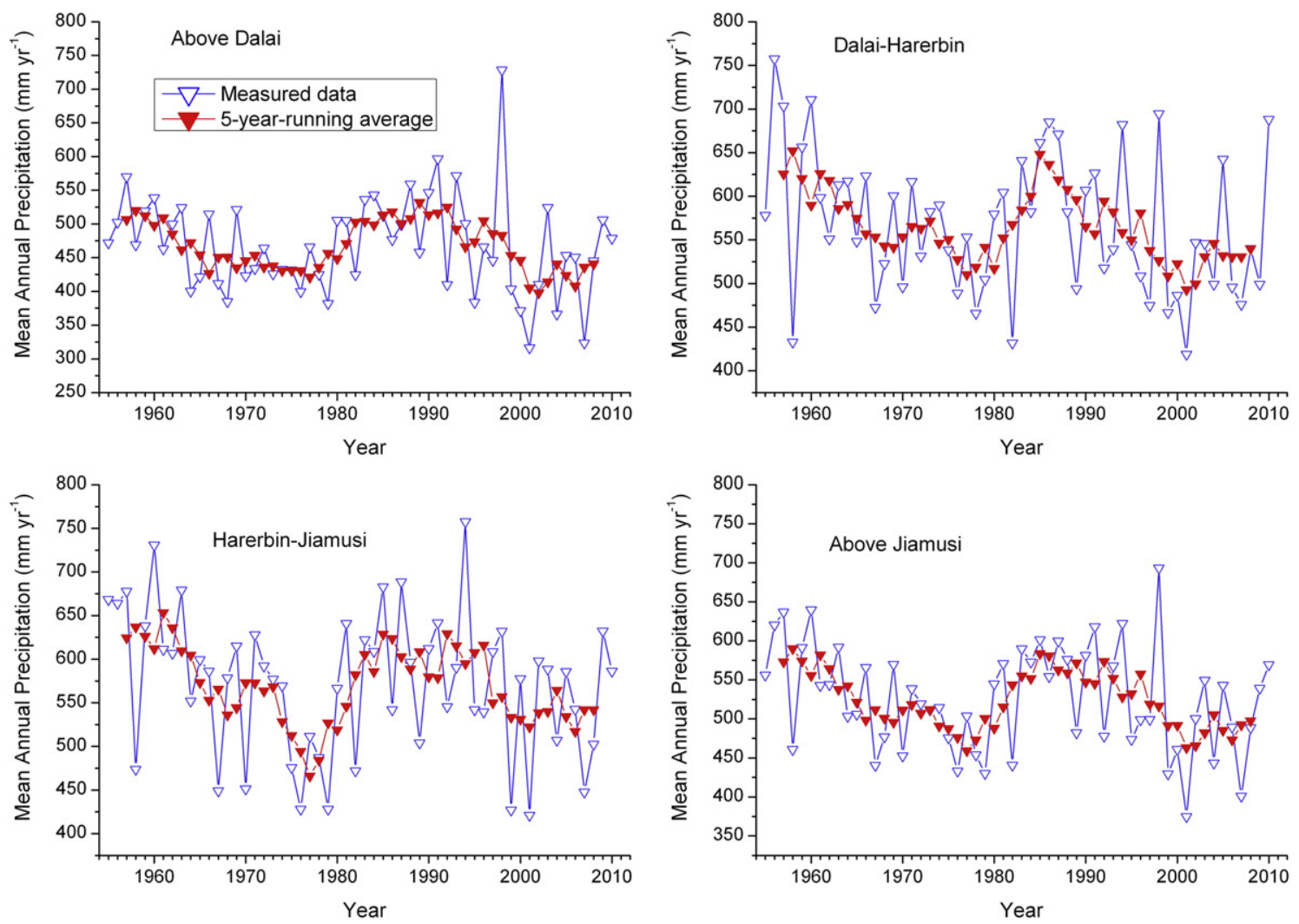

Fig. 6. Mean annual precipitation in the above Dalai, Dalai-Haerbin and Haerbin-Jiamusi sections and the whole Songhua River basin. 

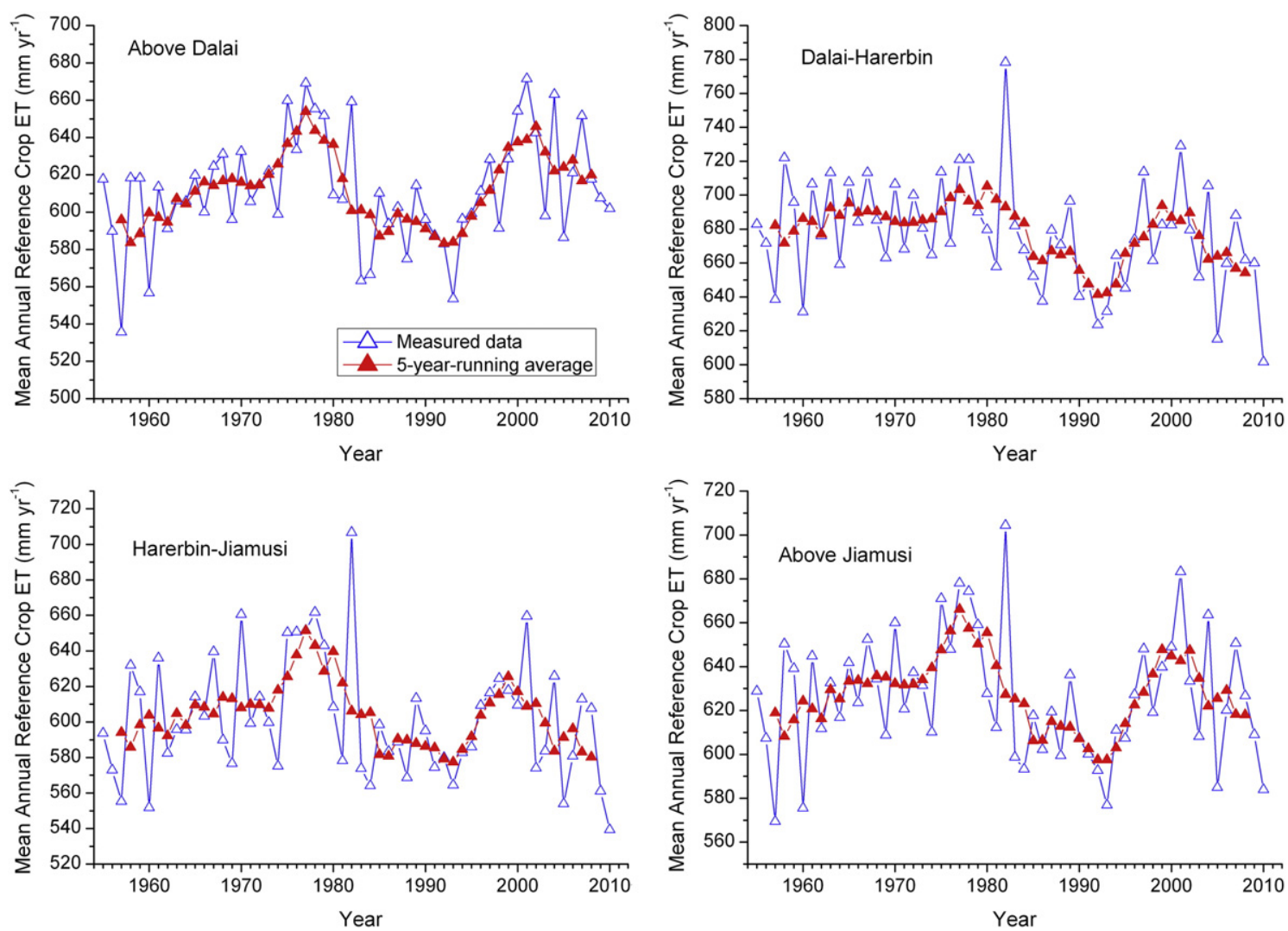

Fig. 7. Mean annual potential ET in the above Dalai, Dalai-Haerbin and Haerbin-Jiamusi sections and the whole Songhua River basin.

changes at this station could largely reflect the runoff dynamics of the whole river basin.

With respect to the whole river basin, three turning years of 1966 , 1982, and 1998 in the runoff changes were identified (Fig. 11). Accordingly, the runoff changes for the whole river basin were divided as the reference baseline period of 1955-1966 (with mean annual runoff of $830.7 \times 10^{8} \mathrm{~m}^{3} \mathrm{yr}^{-1}$ ) and the measure periods of 1967-1982, 1983-1998, and 1999-2010. The relationships between year and cumulative runoff, precipitation, and potential ET for different periods were illustrated in Fig. 11. It is evident that each relationship has a very high correlation coefficient. The slope $\left(S_{P}, S_{E T}\right)$ of each fitted line is extracted from the equations as shown in Fig. 11 and listed in Table 2.

Based on Eqs. ((2)-(4)) and the parameters $S_{R}$ and $S_{E T}$ in Table 2, the quantitative impacts of climatic and anthropogenic factors on the runoff changes for the whole river basin were calculated (Table 3). The magnitude of impact of precipitation, potential ET, and human activities is $33.4,11.0$, and $55.6 \%$ for the period of $1967-1982,10.1,-15.7$, and $105.7 \%$ for the period of $1983-1998$, and $28.1,2.6$, and $69.2 \%$ for the period of 1999-2010, respectively.

\section{Discussion}

\subsection{Multiple phases in the runoff changes}

Most previous studies show that the runoff changes in a complete river basin or its sub-basins over the last decades are characterized by only one turning year. For example, 1971 is the turning year in the runoff changes for the Wuding River during the period 1956-1996
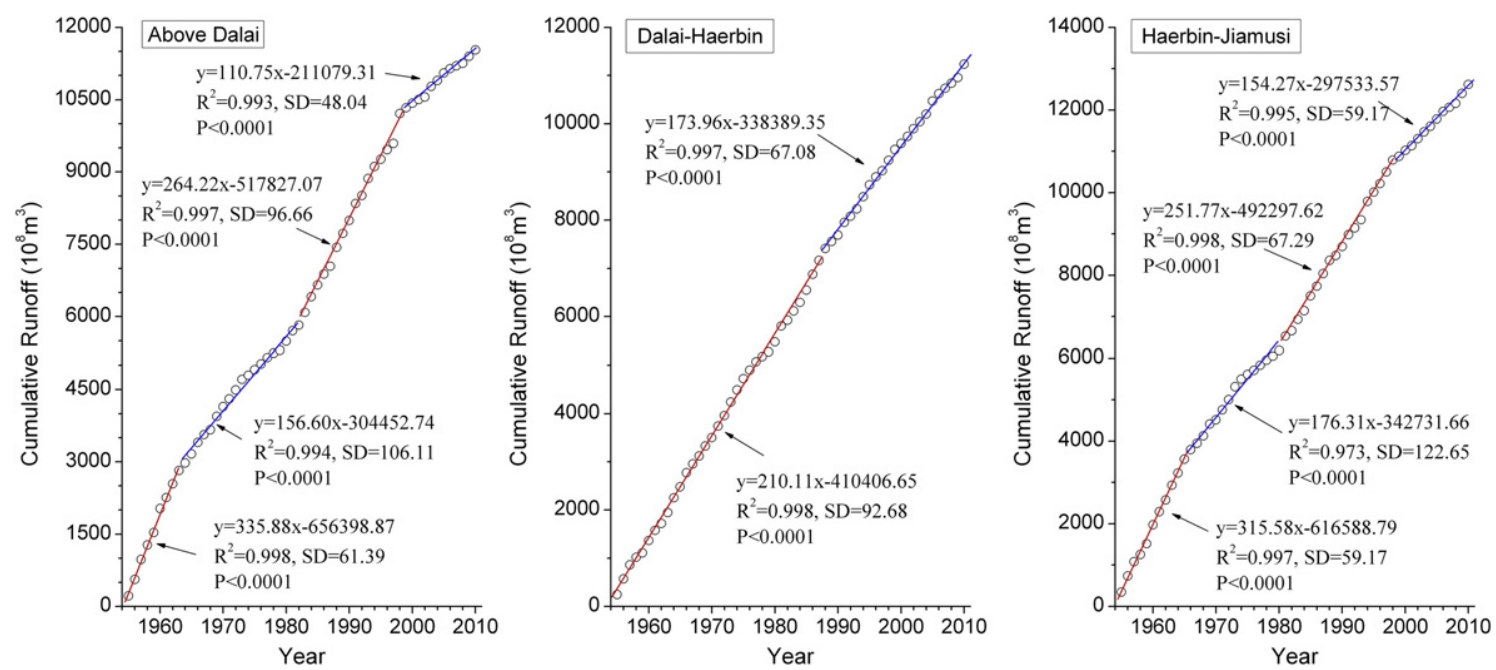

Fig. 8. Relationships between year and cumulative runoff for the three sections of the Songhua River. 

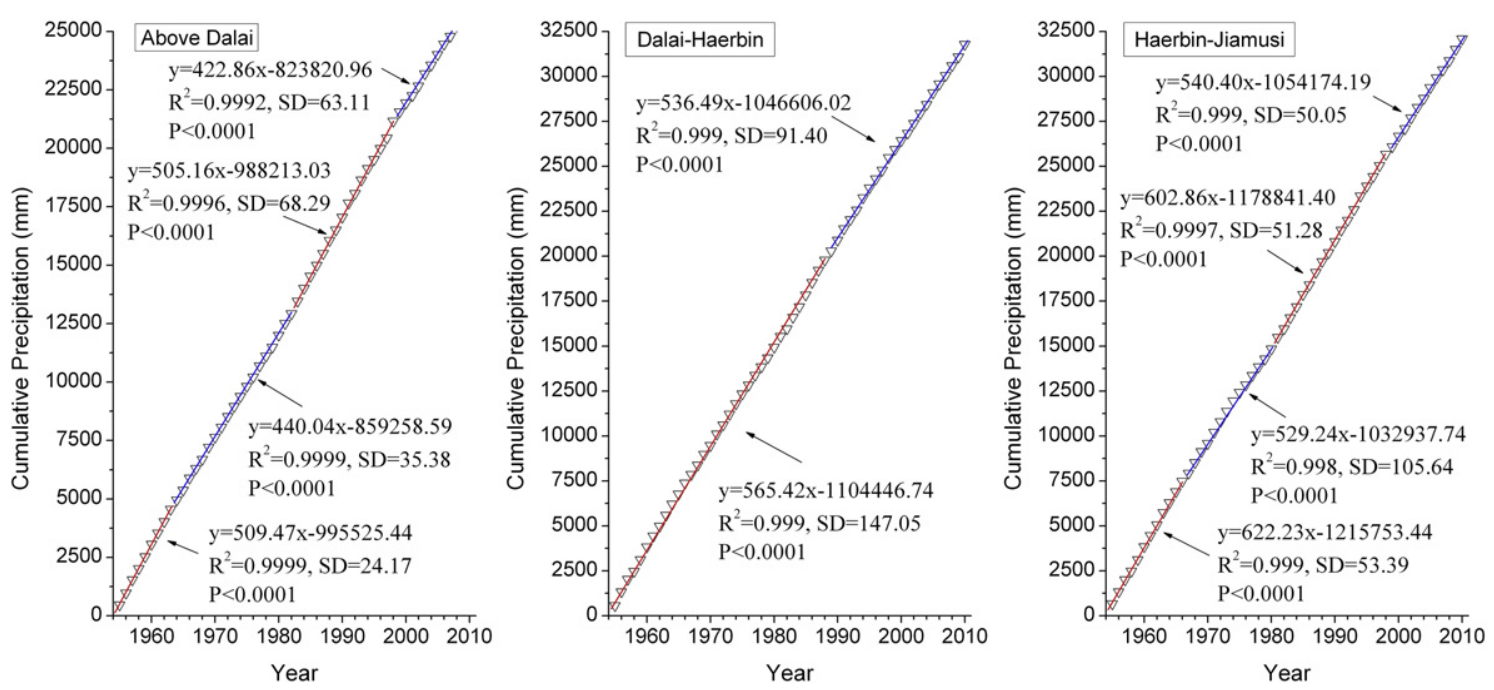

Fig. 9. Relationships between year and cumulative precipitation for the three sections of the Songhua River.

(Xu, 2011), 1973 for the Kuye River during the period 1954-1993 (Zhao et al., 2010), and 1992 for the Weihe River basin during the period 1956-2000 (Wang et al., 2008). Further, for the whole Yellow River basin, only one turning year in the runoff changes was detected for the period 1950-2009 (Wang et al., 2012a). This single turning year can be used to divide the whole study period into two individual phases, including the reference baseline period and the measure period. In the Songhua River basin, although only one turning year was identified for the Dalai-Haerbin sub-basin, three different turning years were detected for the other two sub-basins (above Dalai and Haerbin-Jiamusi) and for the whole basin. This indicates that runoff changes in the two sub-basins and in the whole river basin are characterized by four different phases, one reference baseline period and three measure periods. Identification of multiple turning years suggests that the observed runoff changes are the combined results of natural and enhanced anthropogenic factors over the past decades. Differences in the turning year indicate different beginnings of crucial anthropogenic influences on the runoff changes among the sub-basins, in particular between the Dalai-Haerbin sub-basin and the others.

\subsection{Climatic impacts on runoff changes}

Compared with the baseline reference period, the mean annual runoff decreased significantly almost in all the measure periods for each individual sub-basin and for the whole Songhua River basin. Precipitation and ET are direct influencing factors on runoff changes for any river basins (Wang et al., 2012a). Decreasing precipitation and increasing ET play critical roles in affecting the reduced runoff changes. However, if the reduced magnitude of precipitation is greater than that of ET, decreases in both precipitation and ET would also lead to reduced runoff changes.

The obtained results show that the impacts of precipitation on runoff changes range from 3.3 to $33.9 \%$, while the impacts of potential ET range from -15.7 to $11.0 \%$. Furthermore, negative impacts on the runoff changes from potential ET can be found in the measure periods of 1989-2010 for the Dalai-Haerbin sub-basin, and 1981-1998 and 1999-2010 for the Haerbin-Jiamusi sub-basin. However, the decreasing proportion in precipitation is greater than that in potential ET for those measure periods. As a result, climate in these sub-basins generally
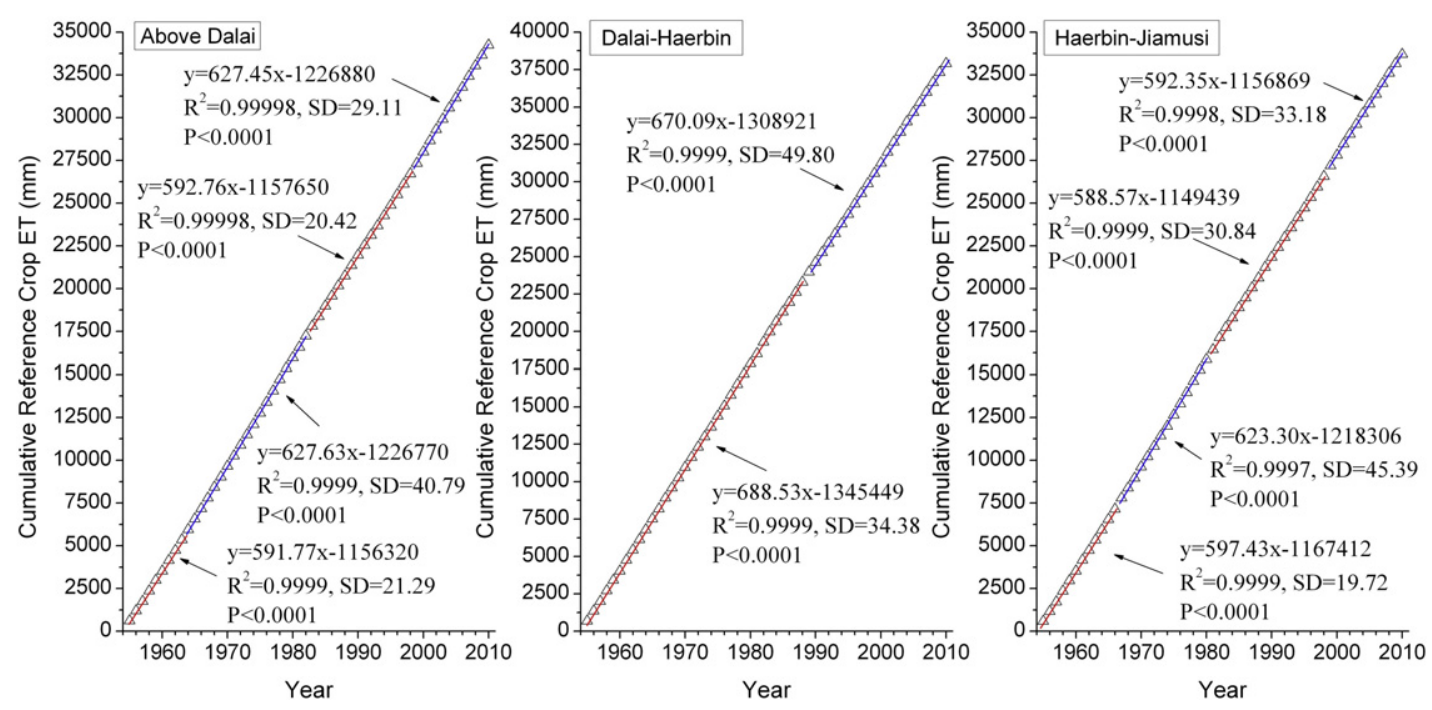

Fig. 10. Relationships between year and cumulative potential ET for the three sections of the Songhua River. 
Table 3

Slope change ratios of the fitted lines and the quantitative impacts of precipitation, potential ET and human activities on runoff changes for different sections during different periods.

\begin{tabular}{|c|c|c|c|c|c|c|c|c|}
\hline \multirow[t]{2}{*}{ Regions } & \multicolumn{2}{|c|}{ Periods } & \multicolumn{3}{|c|}{ Change ratio (\%) } & \multicolumn{3}{|c|}{ Quantitative influences (\%) } \\
\hline & & & $\Delta S_{R}$ & $\Delta S_{P}$ & $\Delta S_{E T}$ & $C_{P}$ & $C_{E T}$ & $C_{H}$ \\
\hline \multirow[t]{4}{*}{ Above Dalai } & Baseline & 1955-1963 & & & & & & \\
\hline & Measure & 1964-1982 & 56.00 & 13.63 & 6.06 & 24.3 & 10.8 & 64.8 \\
\hline & & 1983-1998 & 25.76 & 0.85 & 0.17 & 3.3 & 0.6 & 96.1 \\
\hline & & $1999-2010$ & 68.88 & 17.00 & 6.03 & 24.7 & 8.8 & 66.6 \\
\hline \multirow[t]{2}{*}{ Dalai-Haerbin } & Baseline & 1955-1988 & & & & & & \\
\hline & Measure & 1989-2010 & 17.21 & 5.12 & -2.68 & 29.7 & -15.6 & 85.8 \\
\hline \multirow[t]{4}{*}{ Haerbin-Jiamusi } & Baseline & $1955-1966$ & & & & & & \\
\hline & Measure & 1967-1980 & 44.13 & 14.94 & 4.33 & 33.9 & 9.8 & 56.3 \\
\hline & & 1981-1998 & 20.22 & 3.11 & -1.48 & 15.4 & -7.3 & 91.9 \\
\hline & & 1999-2010 & 51.12 & 13.15 & -0.85 & 25.7 & -1.7 & 75.9 \\
\hline \multirow[t]{4}{*}{ Above Jiamusi } & Baseline & 1955-1966 & & & & & & \\
\hline & Measure & 1967-1982 & 36.52 & 12.19 & 4.02 & 33.4 & 11.0 & 55.6 \\
\hline & & 1983-1998 & 12.11 & 1.22 & -1.91 & 10.1 & -15.7 & 105.7 \\
\hline & & 1999-2010 & 48.34 & 13.59 & 1.28 & 28.1 & 2.6 & 69.2 \\
\hline
\end{tabular}

shows positive impacts on runoff changes and the magnitude ranges from 4.9 to $43.7 \%$.

For the whole Songhua River basin, similar positive impacts from climate are obvious during the measure periods of 1967-1982 and 1999-2010. However, negative impacts from climate on the runoff changes occurred in the measure period of 1983-1998 (Table 3). Clearly, this negative impact is abnormal because it does not occur in any sub-basins. This is probably caused by the great difference in the turning years of the runoff changes between the Dalai-Haerbin and other sub-basins. Therefore, the quantified climatic impact on runoff changes for the whole river basin could not always reflect its actual impacts for a certain sub-basin. This is particularly true if the turning years are different between runoff changes of the whole river basin and the sub-basins.
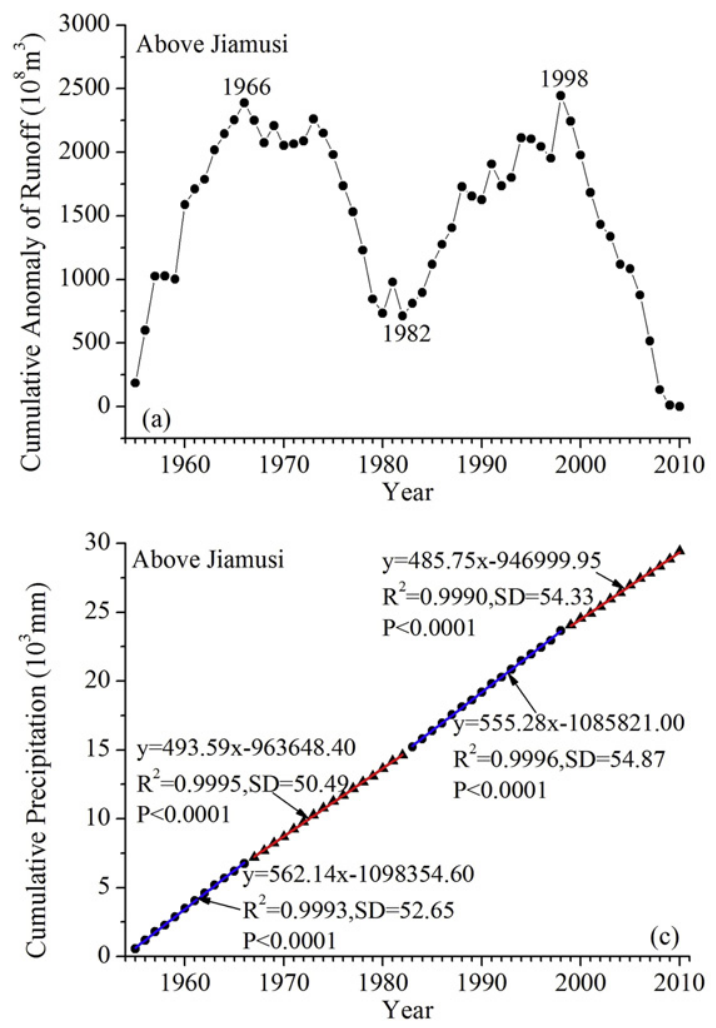

\subsection{Anthropogenic impacts on runoff changes}

The relative impact from human activities on the runoff changes for the three sub-basins ranges from 56.3 to $96.1 \%$, indicating that anthropogenic influence has become the dominant factors in controlling runoff changes during the last decades. This predominance of human over natural factors on runoff changes is similar to that for the Yellow River and its tributaries (e.g., Wang et al., 2012a,b), the Pear River (Wu et al., 2012), and the Huaihe River (Liu and Xia, 2013). Furthermore, the anthropogenic influence in the measure period of 1983-1998 for the above Dalai sub-basin and 1981-1998 for the Haerbin-Jiamusi sub-basin reached the maximum of $96.1 \%$ and $91.9 \%$, respectively. This demonstrates that the relative impact from human activities on the runoff changes has first increased over the period of the 1960s-1990s
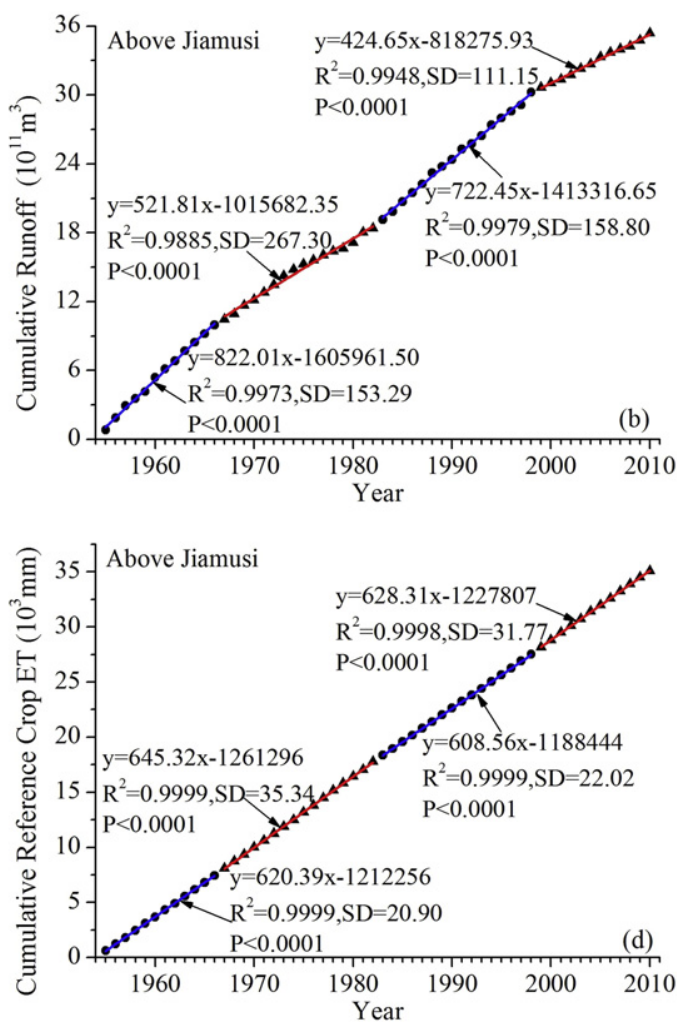

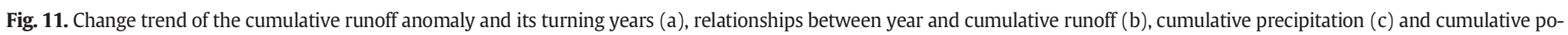
tential ET (d) for the whole Songhua River basin. 
and then decreased during the period of the 1990s-2000s. This increasing-decreasing trend is different from the single increasing trend reported by literature (e.g., Wang et al., 2008; Xu, 2011; Wang et al., 2012a).

With rapid population growth in recent decades, intensity of human activities in the river basin has increased since the 1960s. Given that about half of the basin area is situated within the Heilongjiang Province, variations of population, irrigation area of cultivated land, reservoir capacity, and area of soil conservation in the province could reflect the intensity of human activities. Over the period from 1965 to 2010 in Heilongjiang Province, its population increased from 21.34 million to 38.33 million (National Bureau of Statistics, 2005; Bureau of Statistic of Heilongjiang Province, 1987-2011). With increasing population and food demand, the effective irrigation area of cultivated land expanded from $1791 \mathrm{~km}^{2}$ in 1965 to $3.88 \times 10^{4} \mathrm{~km}^{2}$ in 2010 (National Bureau of Statistics, 2005; Bureau of Statistic of Heilongjiang Province, 1987-2011). As a result, the withdrawn water volume for irrigation increased sharply, and large numbers of reservoirs were constructed. For example, the total storage capacity of reservoirs has increased from 10.27 billion $\mathrm{m}^{3}$ in 1965 (National Bureau of Statistics, 2005) to 175.1 billion $\mathrm{m}^{3}$ in 2010 (Bureau of Statistic of Heilongjiang Province, 1987-2011). Therefore, the river runoff discharge decreased remarkably due to the greatly increased water diversion. Soil conservation is another influencing factor on the runoff reduction in the Songhua River basin. While the total area of soil conservation was only $5500 \mathrm{~km}^{2}$ in 1965 (National Bureau of Statistics, 2005), it has increased to $27,920 \mathrm{~km}^{2}$ in 1998 and further to $46,905 \mathrm{~km}^{2}$ in 2010 (Bureau of Statistic of Heilongjiang Province, 1987-2011). The widely implemented soil conservation measures within the river basin mainly include creation of level terraces, dam construction, afforestation, and grass planting. These conservation measures can effectively alter the local microtopography and hydrological regime, thus reducing the runoff discharge to varying degrees.

The variations of population, irrigation area of cultivated land, reservoir capacity, and area of soil conservation within other three provinces have similar increasing trends as in Heilongjiang Province. Therefore, the impacts of human activities in these provinces on the runoff changes of the Songhua River are similar to that in Heilongjiang Province.

Although both the population and the area of irrigated farmland and soil conservation in the Songhua River basin continued to increase in the 2000s, some lately adopted measures, such as water-saving irrigation, wetland conservation and restoration, and reforestation, constrained water demand from the river. Climatic influence on the runoff changes of the river during this period was more efficient than that in the previous periods. As a result, the relative impacts from human activities on the runoff changes decreased remarkably. Even so, it is worth noting that human activities play a dominant role in controlling the runoff changes for the Songhua River even now.

\section{Conclusions}

Using observed records of annual runoff at three gauging stations along the Songhua River and of annual precipitation and potential evapotranspiration from 62 meteorological stations during the period 1955-2010, we analyzed the temporal changes of runoff during the period 1955-2010. Based on identified turning years in runoff changes, we further quantified the relative impacts of climatic and anthropogenic factors on runoff.

(1) Three turning years of 1963, 1982, and 1998 for the above Dalai sub-basin, of 1966, 1980, and 1998 for the Haerbin-Jiamusi sub-basin, and of 1966, 1982, and 1998 for the whole river basin were identified. With the turning years, one reference baseline period and three measure periods were divided. However, only one turning year of 1988 was found and thus a reference baseline period and a measure period were divided for the Dalai-Haerbin sub-basin.
(2) For the runoff changes in the above Dalai and Haerbin-Jiamusi sub-basins, the impact of precipitation ranged from 3.3\% to $24.7 \%$ and from $15.4 \%$ to $33.9 \%$, respectively. In comparison, the impact of evapotranspiration ranged from $0.6 \%$ to $10.8 \%$ and from $-7.3 \%$ to $9.8 \%$, respectively, while the anthropogenic impact ranged from $64.8 \%$ to $96.1 \%$ and from $56.3 \%$ to $91.9 \%$, respectively. For the runoff changes in the Dalai-Haerbin sub-basin, the impact of precipitation, evapotranspiration, and human activities was $29.7 \%,-15.6 \%$, and $85.8 \%$, respectively. Anthropogenic impact has become a dominant factor in controlling runoff changes in the river basin.

(3) The anthropogenic impact reached its maximum in the 1990s, and then decreased remarkably as a result of the implementation of some new measures, such as water-saving irrigation, wetland conservation and restoration, and reforestation, for the purpose of agriculture production and environment protection. Given the severe water stress, anthropogenic impact on runoff changes within the river basin must be given more attention in the future.

\section{Acknowledgments}

This study is supported by the National Science Foundation of China (Grant No. 41271027) and the National Basic Research Program of China (Grant No. 2010CB428404). We are grateful to the Editor, Estela Nadal-Romero, and two anonymous reviewers for their constructive comments. Thanks are also given to Dr Guanie Lim for his help in polishing English.

\section{References}

Allen, R.G., Pereira, L.S., Raes, D., et al., 1998. Crop evapotranspiration-guidelines for computing crop water requirements. FAO Irrigation and Drainage. No. 56.

Arnell, N.W., 1999. Climate change and global water resources. Glob. Environ. Chang. 9 (1), S31-S49.

Askew, A.J., 1987. Climate change and water resources. IAHS Publication 168, pp. 421-430.

Bureau of Hydrology, Ministry of Water Resources of People's Republic of China, 1955-2010. Hydrologic data of Heilongjiang River Basin.

Bureau of Statistic of Heilongjiang Province, 1987-2011. Heilongjiang Statistical Yearbook. China Statistics Press, Beijing.

Burn, B.H., 1994. Hydrologic effects of climatic change in west-central Canada. J. Hydrol $160,53-70$.

Cao, L., Zhang, Y., Shi, Y., 2011. Climate change effect on hydrological processes over the Yangtze River basin. Quat. Int. 244 (2), 202-210.

Chiew, F.H.S., McMahon, T.A., 2002. Modelling the impacts of climate change on Australian stream flow. Hydrol. Process. 16, 1235-1245.

Drogue, G., Pfister, L., Leviandier, T., El Idrissi, A., Iffly, J., Matgen, F.P., Humbert, J., Hoffmann, L., 2004. Simulating the spatio-temporal variability of streamflow response to climate change scenarios in a mesoscale basin. J. Hydrol. 293 (1-4), 255-269.

Feng, X., Zhang, G., Yin, X., 2011. Hydrological responses to climate change in Nenjiang River basin, northeastern China. Water Resour. Manag. 25 (2), 677-689.

Islam, A., Sikka, A.K., Saha, B., Singh, A., 2012. Streamflow response to climate change in the Brahmani River Basin, India. Water Resour. Manag. 26, 1409-1424.

Lei, H., Yang, D., Huang, M., 2014. Impacts of climate change and vegetation dynamics on runoff in the mountainous region of the Haihe River basin in the past five decades. J. Hydrol. 511, 786-799.

Liu, R., Xia, J., 2013. Influence analysis of climate change and human activities on runoff of the upper Huaihe River. Yellow River 35 (9), 30-33 (in Chinese).

Liu, Z., Xia, Z., Yu, L., Wang, J., 2012. Temporal and spatial variation of characteristics of precipitation in Songhua River Basin during 1958-2009. J. Nat. Resour. 27 (6), 990-1000 (in Chinese).

Ma, Z., Kang, S., Zhang, L., Tong, L., Su, X., 2008. Analysis of impacts of climate variability and human activity on streamflow for a river basin in arid region of northwest China. J. Hydrol. 352 (3-4), 239-249.

McCabe, G.J., Wolock, D.M., 2011. Independent effects of temperature and precipitation on modeled runoff in the conterminous United States. Water Resour. Res. 47 (W11522), 1-11.

Meng, D., Mo, X., 2012. Assessing the effect of climate change on mean annual runoff in the Songhua River basin, China. Hydrol. Process. 26 (07), 1050-1061.

Merritt, W.S., Alila, Y., Barton, M., Taylor, B., Cohen, S., Neilsen, D., 2006. Hydrologic response to scenarios of climate change in subwatersheds of the Okanagan basin, British Columbia. J. Hydrol. 326, 79-108.

Miao, C., Yang, L., Liu, B., Gao, Y., Li, S., 2011. Streamflow changes and its influencing factors in the mainstream of the Songhua River basin, Northeast China over the past 50 years. Environ. Earth Sci. 63, 489-499. 
Milliman, J.D., Farnsworth, K., Jones, P., Xu, K., Smith, L.C., 2008. Climatic and anthropogenic factors affecting river discharge to the global ocean, 1951-2000. Glob. Planet. Chang. 62, 187-194.

National Bureau of Statistics, 2005. China Compendium of Statistics, 1949-2004. China Statistics Press, Beijing.

Nilsson, C., Reidy, C.A., Dynesius, M., Revenga, C., 2005. Fragmentation and flow regulation of the world's large river system. Science $308,405-408$.

Pan, J., Tang, L., 2013. Distributed hydrological simulation and runoff variation analysis for the upper basin of Songhua River. J. Hydroelectr. Eng. 32 (5), 58-63.

Penman, H.L., 1948. Natural evaporation from open water, bare soil and grass. The Roya Society, pp. $120-145$

Poveda, G., Jaramillo, A., Gil, M., Quiceno, N., Mantilla, R., 2001. Seasonality in ENSOrelated precipitation, river discharges, soil moisture, and vegetation index in Colombia. Water Resour. Res. 37 (8), 2169-2178.

Richey, J.E., Nobre, C., Deser, C., 1989. Amazon River discharge and climate variability: 1903-1985. Science 246, 101-103.

Schulze, R.E., 2000. hydrological responses to land use and climate change: a southern African perspective. Ambio 29 (1), 12-22.

Song, X., Mu, X., Gao, P., Wang, F., Wang, S., 2009. Trends of runoff variation from 1900 to 2005 at Haerbin Station of Songhua River. J. Nat. Resour. 24 (10), 1803-1809 (in Chinese).

Tang, C., Crosby, B.T., Wheaton, J.M., Piechota, T.C., 2012. Assessing streamflow sensitivity to temperature increases in the Salmon River Basin, Idaho. Glob. Planet. Chang. 88-89, 32-44

Vörösmarty, C.J., Green, P., Salisbury, J., Lammers, R., 2000. Global water resources: vulnerability from climate change and population growth. Science 289, 284-288.

Wang, S., Wei, H., Zheng, X., 2008. Analysis of the runoff sequence change trend and inflexion in the Weihe River. Water Resour. Res. 29 (3), 1-2 (in Chinese).
Wang, S., Yan, M., Yan, Y., Shi, C., He, L., 2012a. Contributions of climate change and human activities to the changes in runoff increment in different sections of the Yellow River. Quat. Int. 282, 66-77.

Wang, S., Yan, Y., Yan, M., Zhao, X., 2012b. Quantitative estimation of the impact of precipitation and human activities on runoff change of the Huangfuchuan River basin. J. Geogr. Sci. 22 (5), 906-918.

Wang, Y., Wang, S., Su, T., 2014. Quantification of impacts of precipitation and human activities on runoff changes in different sections of Songhua River during 1955-2010. Prog. Geogr. 33 (1), 65-75 (in Chinese).

Wu, C.S., Yang, S.L., Lei, Y.P., 2012. Quantifying the anthropogenic and climatic impacts on water discharge and sediment load in the Pearl River (Zhujiang), China (1954-2009). J. Hydrol. 452-453, 190-204.

Xu, J., 2011. Variation in annual runoff of the Wudinghe River as influenced by climate change and human activity. Quat. Int. 244, 230-237.

Xu, D., Zhang, G., Yin, X., 2009. Runoff variation and its impacting factor in Nenjiang River during 1956-2006. Adv. Water Sci. 20 (3), 416-421.

Yan, Y., Yang, Z., Liu, Q., 2013. Nonlinear trend in streamflow and its response to climate change under complex ecohydrological patterns in the Yellow River Basin, China. Ecol. Model. 252, 220-227.

Yin, Y., Wu, S., Zheng, D., et al., 2008. Radiation calibration of FAO56 Penman-Monteith model to estimate reference crop evapotranspiration in China. Agric. Water Manag. 95 (1), 77-84.

Zhao, X., Wang, S., Fan, X., 2010. Analysis on the change trend of the runoff and influencing factors in the Kuye River basin from 1954 to 1993. J. Water Resour. Water Eng. 21 (5), 32-36 (in Chinese).

Zuo, D.P., Xu, Z.X., Yang, H., et al., 2012. Spatiotemporal variations and abrupt changes of potential evapotranspiration and its sensitivity to key meteorological variables in the Wei River basin, China. Hydrol. Process. 26, 1149-1160. 